
(INR), Karlsruhe Institute of Technology (KIT), 76344 Eggenstein-Leopoldshafen, Germany Guangming.Zhou@kit.edu

\title{
Transient thermal analysis and structural assessment of an ex-vessel LOCA event on the EU DEMO HCPB breeding blanket and the attachment system
}

\author{
Guangming Zhou*, Francisco A. Hernández, Christian Zeile, Ivan A. Maione
}

Introduction
- A 3D slice unit model of EU DEMO HCPB blanket has been developed for transient thermal analysis under an ex-vessel LOCA.
- The radial temperature profile has been re-constructed to the HCPB blanket segments, together with mechanical, gravity and
- The results have been assessed with respect to the French design and construction rules for nuclear mechanical components
RCC-MRx 2012.
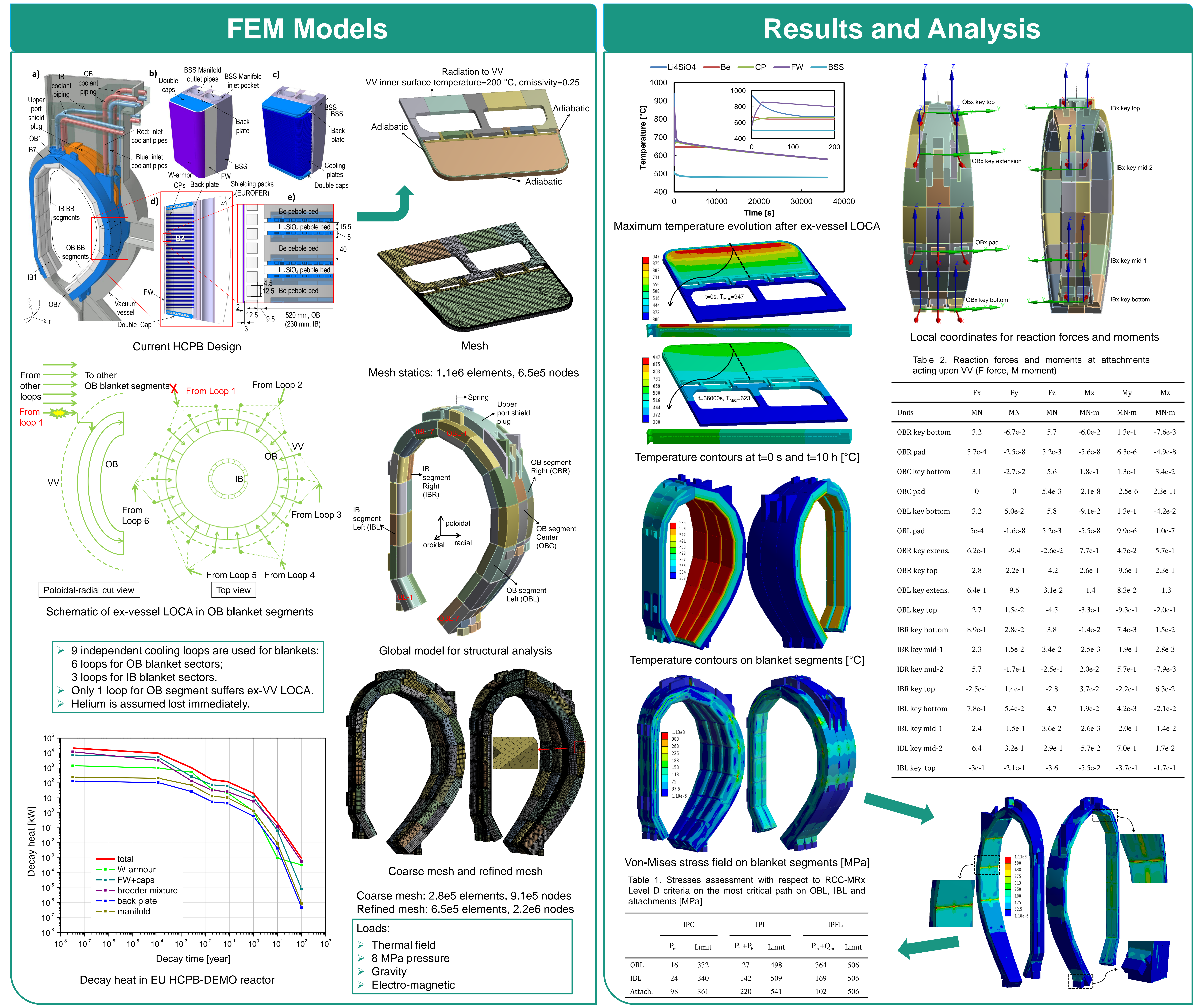

\section{Conclusions}

Transient thermal analysis of the current reference HCPB breeding blanket for EU DEMO baseline 2015 under an ex-vessel LOCA has been presented showing a sufficient cooling down of decay heat by thermal radiation to VV after accident.

- The structural assessment of the HCPB BB segments under the selected accident has been conducted, showing large margins against selected damage modes with respect to the RCC-MRx Level D criteria.

The reaction forces and moments at attachments acting on VV under the selected accident are obtained.

KIT - The Research University in the Helmholtz Association www.kit.edu $13^{\text {th }}$ International Symposium on Fusion Nuclear Technology 25-29 September 2017, Kyoto, Japan

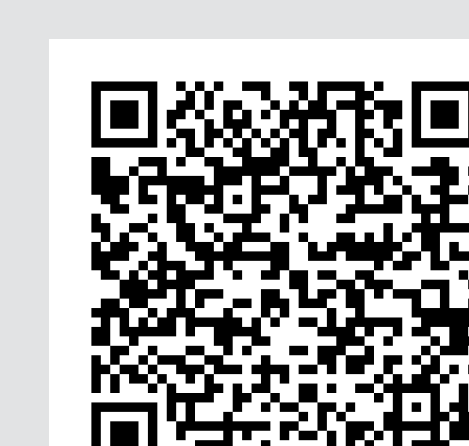

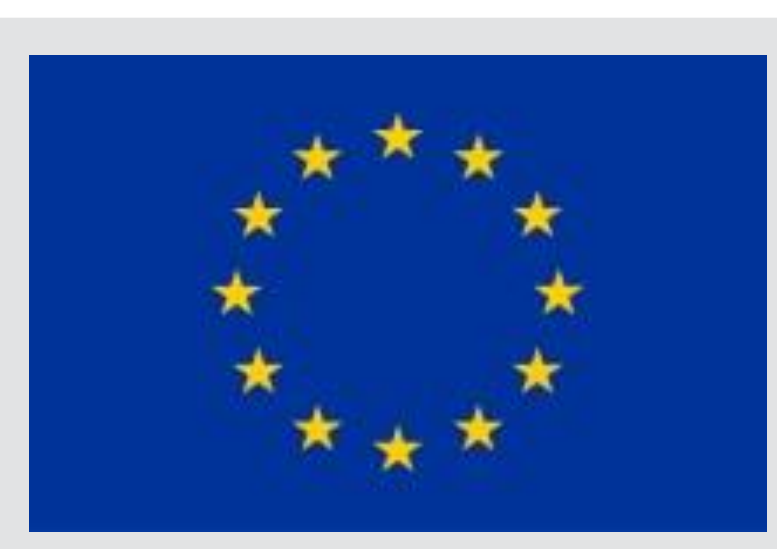

This work has been carried out within the framework of the 2014-2018 under grant agreement No 633053. The reflect those of the European Commission. 